\title{
A Giant Trigeminal Schwannoma, Posterior Fossa and Middle Fossa Extradural Approach: A Case Report
}

\author{
Deb Nath $\mathrm{H}^{1}$, Barua $\mathrm{K} \mathrm{K}^{2}$, Muhammad $\mathbf{M}^{3}$, Hossain $\mathbf{M}^{4}$, Jahan $\mathbf{N}^{5}$, Azam $\mathbf{G}^{6}$, Halder $\mathbf{R}^{7}$, Razib $\mathrm{O}^{8}$
}

Conflict of interest: None

Funding Agency : was not funded by any institute or any group.

Contribution of Authors :

Principal Investigator - Prof. Dr. Haradhan Deb Nath

Data collection- Prof. Kanak Kanti

Barua, Dr. Nur Muhammad

Manuscript preparation- Dr. Manwar

Hossain, Dr. Nowsin Jahan, Dr. Rathin

Halder, Dr. KH Olinur Razib

Editorial formatting- Dr. Gausul Azam

Copyright: @2020bang.BJNS published by BSNS. This article is published under the creative commons CC-BY-NC license. This license permits use distribution (https://creativecommons .orgf/licences/by-nc/4-0/)reproduction in any medium, provided the original work is properly cited and is not used for commercial purposes.

Received: 12 May 2019 Accept: 16 August 2019

\section{Introduction:}

Schwannomas are also known as neurolemmoma, neurinoma and Schwann cell tumors. They originate from Schwann sheath cells. Schwannomas are homogenous tumors that contain only Schwann cells. They comprise $8 \%$ of all central nervous system tumors and they most commonly involve vestibular portion of the $8^{\text {th }}$ cranial nerve. ${ }^{1}$ Their incidence shows a $2: 1$

\begin{abstract}
:
Trigeminal schwannomas are rare tumors that are located in the posterior and middle cranial fossae in about a quarter of the cases. The presentation pattern is different according to the involved compartment and the goal of surgery is complete removal. We present the case of a 28-years old man who presented with a left sided trigeminal schwannomas extending from the posterior to the middle fossa. Middle fossa part of the tumour was removed by extradural subtemporal approach and posterior fossa part was removed by retrosigmoid retromastoid approach.
\end{abstract}

Key words: trigeminal nerve, schwannoma, middle cranial fossa, post fossa.

Bang. J Neurosurgery 2020; 9(2): 162-167 male predilection and the rate of malignant transformation is less than $1 \%$ in all schwannoma cases. $^{2}$

Trigeminal nerve schwannomas (TS) are rare entities, accounting for 1 to $8 \%$ of all intracranial schwannomas and less than $0.4 \%$ of all intracranial tumors. ${ }^{3}$ Women seem to be affected more often than men and the majority of cases present in the third or fourth decade

1. Prof. Dr. Haradhan Deb Nath, Professor, Dept. of Neurosurgery, Bangabandhu Sheikh Mujib Medical University, Dhaka

2. Prof. Kanak Kanti Barua, Professor, Dept. of Neurosurgery, Bangabandhu Sheikh Mujib Medical University, Dhaka

3. Dr. Nur Muhammad, Resident, Dept. of Neurosurgery, Bangabandhu Sheikh Mujib Medical University, Dhaka

4. Dr. Manwar Hossain, Resident, Dept. of Neurosurgery, Bangabandhu Sheikh Mujib Medical University, Dhaka

5. Dr. Nowsin Jahan, Resident, Dept. of Neurosurgery, Bangabandhu Sheikh Mujib Medical University, Dhaka

6. Dr. Gausul Azam, Resident, Dept. of Neurosurgery, Bangabandhu Sheikh Mujib Medical University, Dhaka

7. Dr. Rathin Halder, Resident, Bangabandhu Sheikh Mujib Medical University, Dhaka

8. Dr. KH Olinur Razib, Resident, Bangabandhu Sheikh Mujib Medical University, Dhaka

Address of Correspondence: Prof. Dr. Haradhan Deb Nath, Professor, Dept. of Neurosurgery, Bangabandhu Sheikh Mujib Medical University, Dhaka. Mobile- 01711354120, E-mail: dr.haradhan@yahoo.com 
of life. ${ }^{4}$ The tumors can arise from the trigeminal dorsal root entry zone, the Gasserian ganglion or any of the three branches of the Vth cranial nerve and this variability in origin can lead to complex tumors, which extend in one or in multiple cranial fossae. ${ }^{5}$ The symptomatology is not related to tumor size as most patients usually present with mild facial hypoesthesia, various visual disturbances, and sometimes facial pain. ${ }^{6}$ Various authors presented their series in the literature, but surgical experience in giant trigeminal schwannomas is still limited. We present a case of a giant trigeminal schwannoma and perform a short review of the current literature.

In this case report we present a rare case of giant trigeminal schwannoma and provide the histopathological findings.

\section{Case Report :}

A 28 years age male patient had been admitted at the department of neurosurgery, Bangabandhu Sheikh Mujib Medical University, with the complaints of tingling and numbness of left side of face for 12 months. Imbalance and tedency to fall towards the left side for 2.5 months.

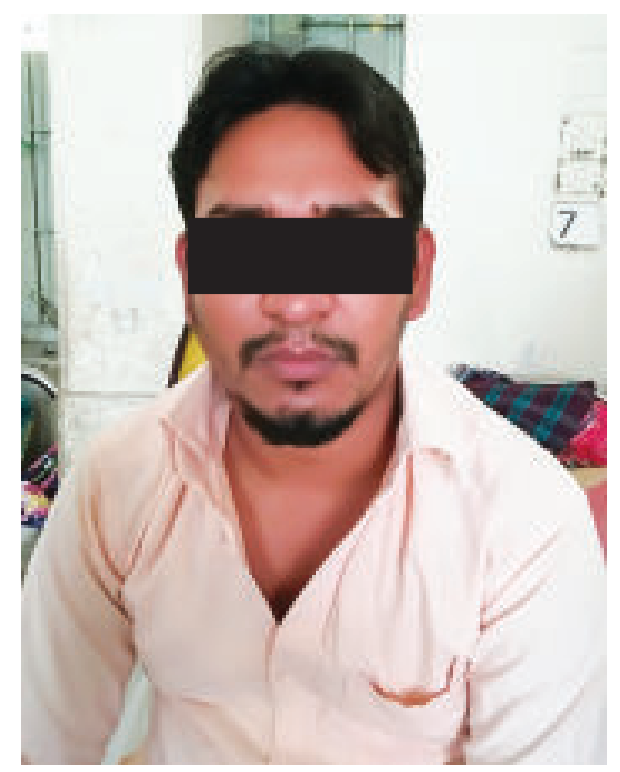

Fig.-1: Preoperative photograph of patient.

According to the statement of the patient he was reasonably well 4.5 months back. Then he noticed tingling and numbness to left side of face. This symptom was not associated with pain.
Patient also complaints of deviation of angle of mouth towards right side and dribbling of saliva from left side of mouth started 12 months back and it improved with medication (steroid). Now he has no deviation of angle of mouth and can close his eyes completely.

He also complains of difficulty in walking and tendency to fall towards left for 2.5 months which is gradually increasing. He complains of difficulty in chewing foods by left jaw for last 3 months and also difficulty in swallowing food and nasal regurgitation of foods for 2 months. On enquiry he gave history of headache of left side of head for same duration which was on left temporal region, insidious in onset, intermittent, not progressive, mild dull aching in nature, occurred any time in day and night, there was no definite aggravating or relieving factor, was associated with vomiting for 2 times at early night in last 6 months. He does not give any history of visual disturbance, fever, cough, hemoptysis, weight loss, convulsion, unconsciousness, bowel bladder abnormality ,weakness of any part of body.

On neurological examination: All cranial nerve normal except trigeminal nerve, cochlear nerve and glossopharyngeal nerve.

Trigeminal nerve: Sensory (pain, touch, temperature) was normal in right side. In left side along V1, V2 and V3 distribution. Motor was normal in right side and masseter muscle wasting present in left side. Jaw jerk was normal in right side. Corneal reflex was absent at left side.

Glossopharyngeal and vagus and cranial accessory - Gag reflex was absent in left side, palatal movement was diminished was left side. Other functions were normal.

\section{Motor and sensory functions were normal.}

Cerbellar function- Scanning speech was present. Heel-shin test positive at right side, pendular knee jerk present at the left side, Gait- tends to fall toward left side, Broadbase gait was present, Nystagmusbilateral horizontal nystagmus present, CT scan and MRI of brain contrast showed left sided trigeminal, schwannoma, Patient was operated in two stage. $1^{\text {st }}$ operation was done by extrdural subtemporal approach. $2^{\text {nd }}$ operation was done by retromastoid, retrosigmoid approach. We have put an EVD through the Kocher's point prior to second surgery. Tumour was removed completely. Postoperatively lower cranial nerve function worsen 


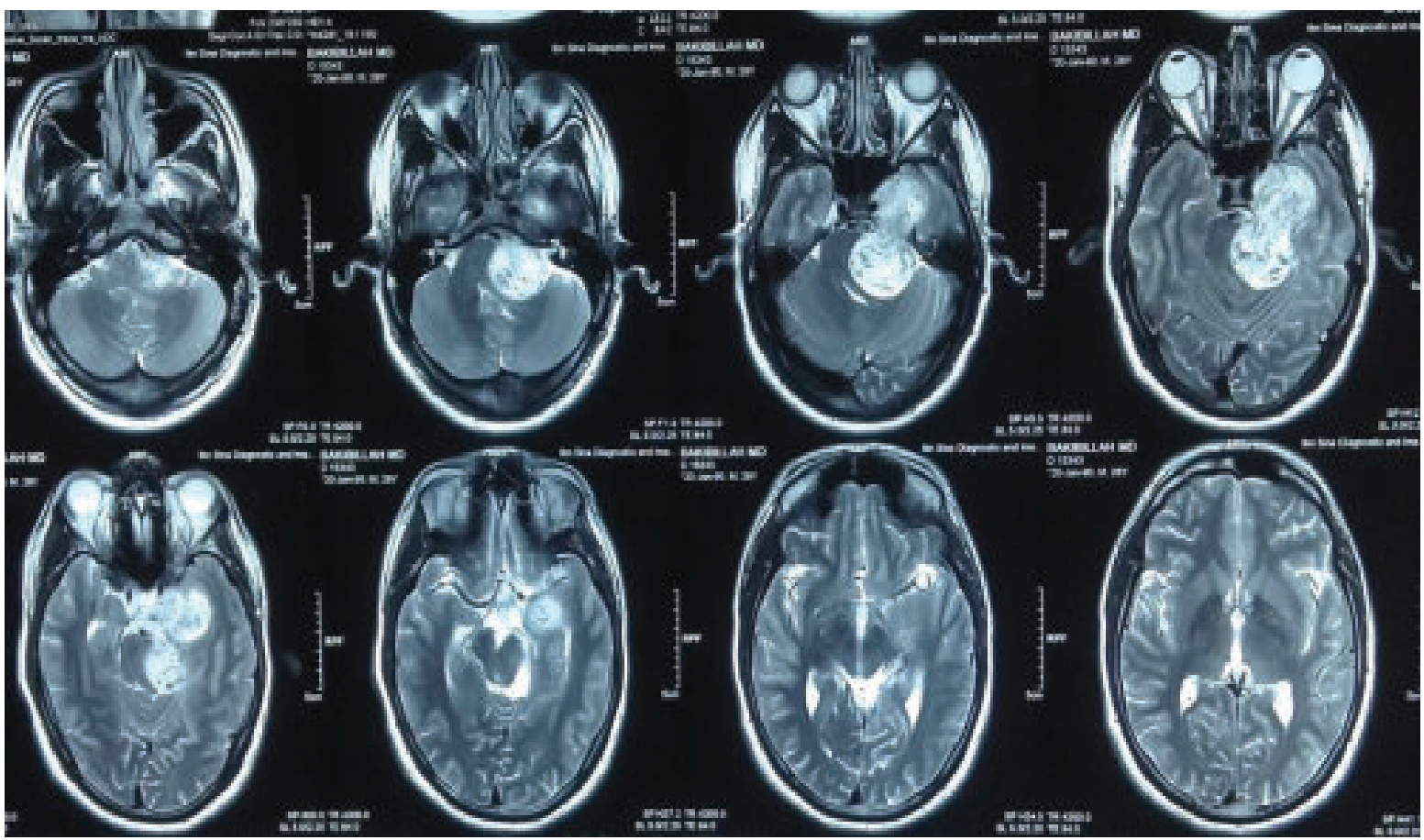

Fig.-2: Preopertive MRI brain showed left trigeminal schwannomas.
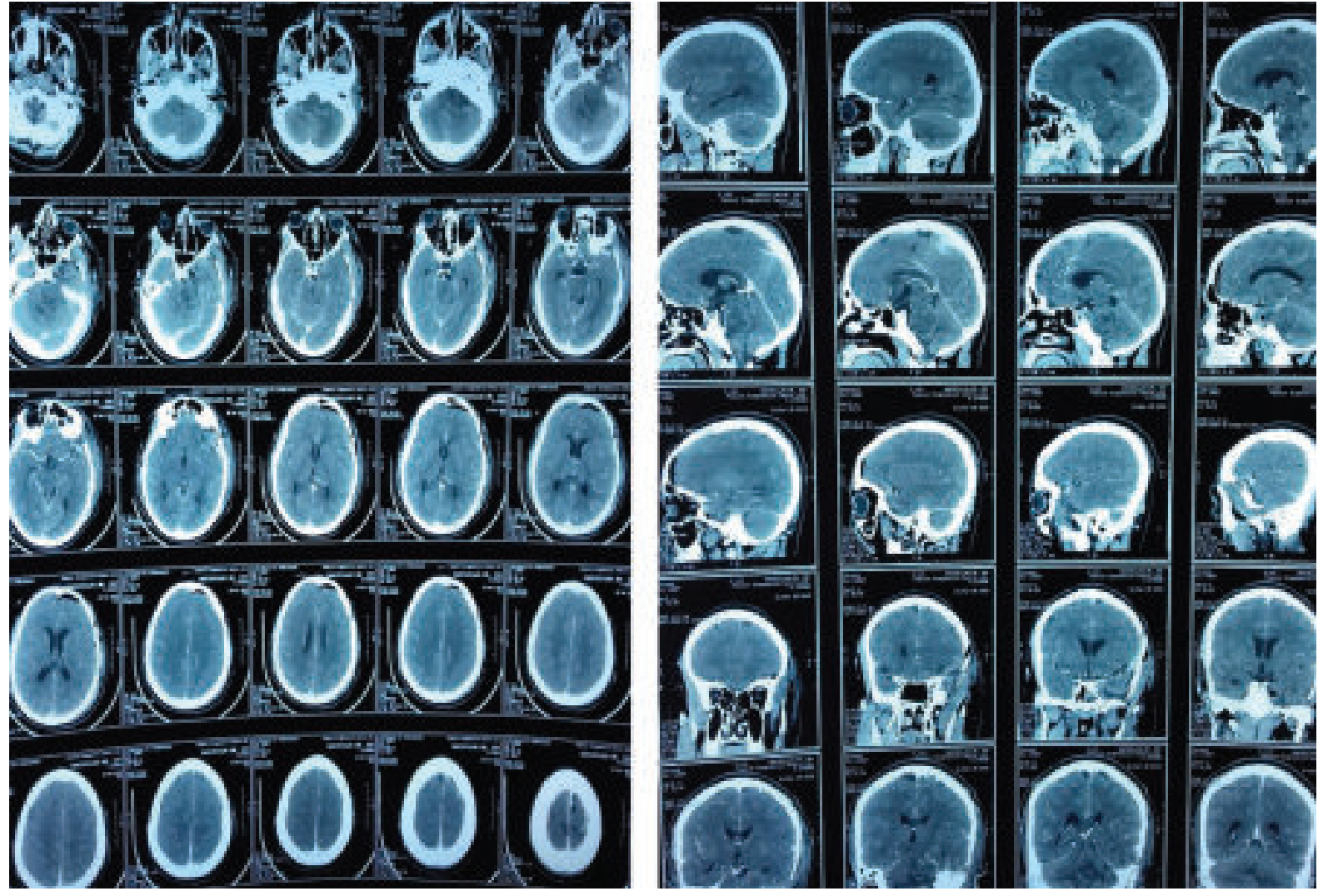

Fig.-3: Postoperative CT scan showed there is residual tumour at left CP angle region. 


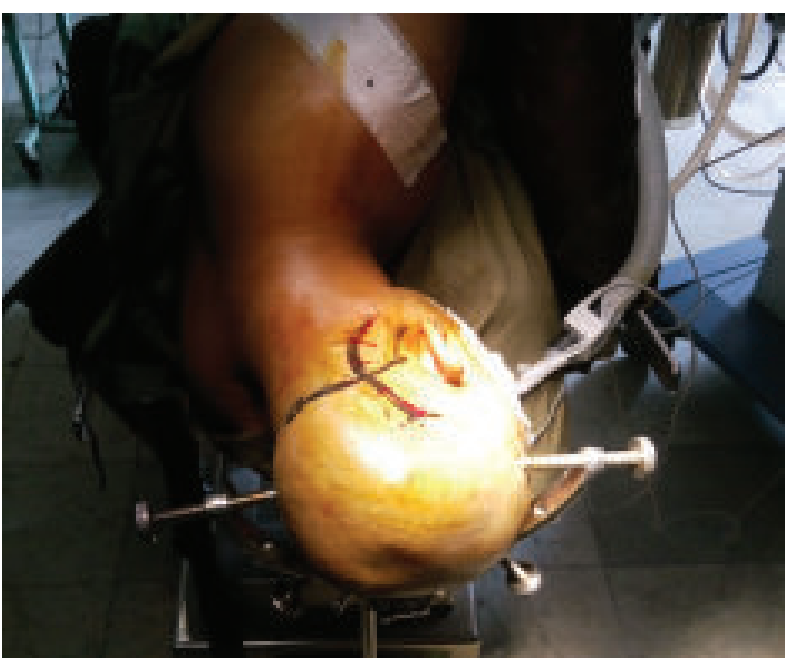

Fig.-4: Peroperative photograph during second surgery.

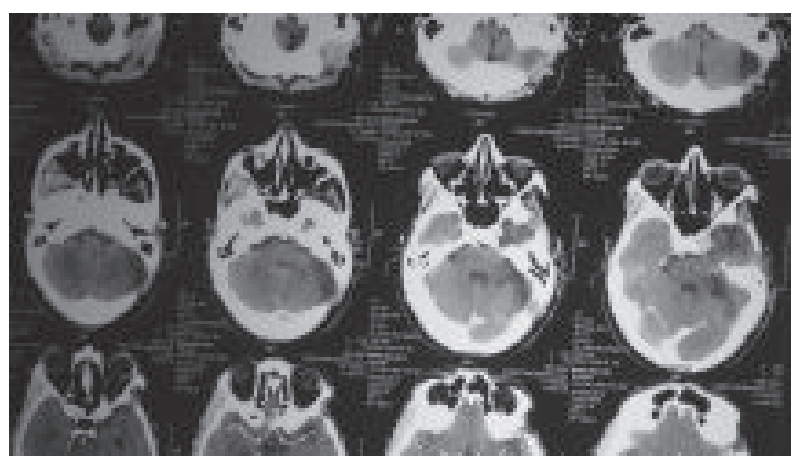

Fig.-5: Postoperative CT scan of brain showed there is no tumour at both posterior fossa and middle fossa.

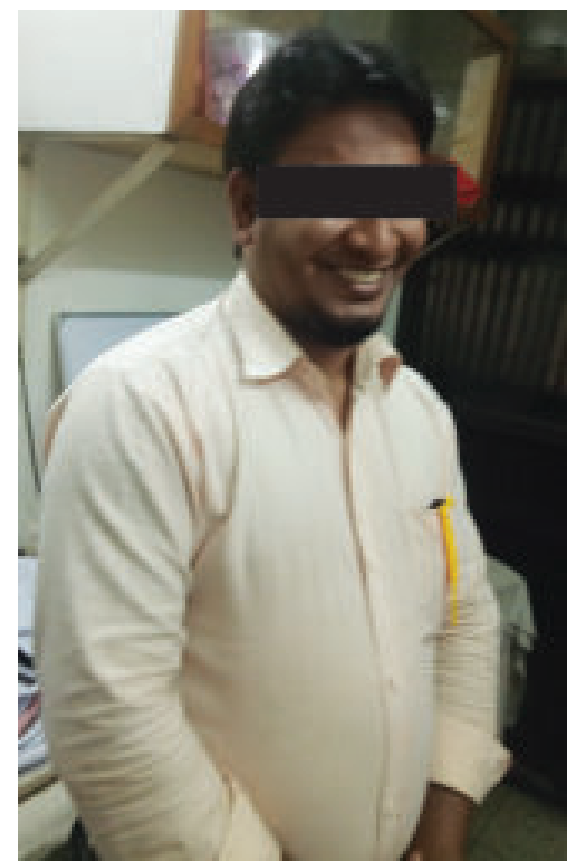

Fig.-6: Postoperative photograph of patients. before than surgery. We gave Ryle's tube peroperatively. Patients used to take food through the Ryle's for two months. Later on cranial nerve function improved gradually and we removed the Ryle's tube.

\section{Discussion:}

Clinical presentation determined by the location of the tumor. Headache, seizures and focal neurological deficits are the most common symptoms. ${ }^{7}$ For the schwannomas with typical locations, the radiological studies may reveal characteristic signs such as isodense or hypodense masses on CT imaging. Similarly, MR imaging may reveal lesions with hypointensity on T1W and iso- or hyperintensity on T2W imaging with heterogeneous contrast enhancement after gadolinium injection. Our patient had an isointense lesion on T1W images and heterogeneous contrast enhancement after contrast injection.

These Schwannomas have been suggested to grow from the Schwann cells in the perivascular nervous plexus $^{8}$ or by transformation of the primitive multipotent mesenchymal cells into Schwann cells. ${ }^{9}$ They were also proposed to result from a migration defect of the neural crest cells during central nervous system development. ${ }^{1,10}$

Radiological and pathological differential diagnosis for these tumors includes pilocytic astrocytoma, lymphoma, pleomorphic xanthoastrocytoma, meningioma, ganglioglioma, metastasis and solitary fibrous tumor (SFT). ${ }^{11}$ During the histological differential diagnosis, fibrillary astrocytoma was ruled out with IDH negativity, solitary fibrous tumor was ruled out with CD34 negativity, fibrous meningioma was ruled out by showing lack of expression for progesterone receptor and epithelial membrane antigen (EMA). A previously proposed immunoreactivity chart for the differential diagnosis of schwannomas, neurofibromas and some other common cerebral tumors. ${ }^{12}$

In 1953, Jefferson tried to characterize trigeminal schwannomas and designed a classification which divided these tumors into three categories, according to their origin. ${ }^{13}$ Type $\mathrm{A}$ included tumors originating anterior of the Gasserian ganglion and located in the middle cranial fossa, type $B$ included tumors in the posterior fossa, originating from the trigeminal root and type $\mathrm{C}$ defined tumors located both in the posterior and middle cranial fossae. ${ }^{13}$ Yoshida and Kawase also offered a classification of TS into six categories 
and divided those that affect multiple cranial fossae. ${ }^{14}$ About $25 \%$ of tumors appear in multiple compartments and because of the rarity of TS, these tumors are infrequent and no standard treatment exists. ${ }^{15}$ What authors agree on is the fact that complete surgical excision is usually curative and as such, whenever feasible, this should be the goal of surgery. ${ }^{16}$

Whenever TS arise from the root of the trigeminal nerve, they involve the posterior fossa. ${ }^{17}$ Because of the fact that they can also appear on any of the nerve branches, these tumors can also grow epidurally into the infratemporal fossa or orbit [5]. Pathological findings are usually those of any schwannoma, but it must be considered that in about $1 \%$ of cases these tumors are associated with neurofibromatosis and therefore other consecutive tumors or, very rarely, a type of melanotic tumor can occur in the trigeminal nerve. ${ }^{14}$

The trigeminal nerve has a mix component, of both sensory and motor fibers. Therefore symptoms of decreased facial sensibility or diminished force of mastication can raise the suspicion of a TS. ${ }^{18}$ Facial hypoesthesia is the initial symptom in $60 \%$ of cases, but it must be kept in mind that because of their large size, symptoms related to any other cranial nerve, cerebellar or brainstem symptoms are also possible. ${ }^{19}$ Radiological appearance plays a pivotal role in diagnosing and planning the surgical treatment of TS. MRI is the method of choice. Tumors usually appear as hypo or isointense on T1 and as hyperintense on T2-weighted imaging, with high enhancement after contrast administration. ${ }^{18}$ A CT scan offers a complementary view of these tumors, as it can demonstrate the existence of bone erosion. Usually, contrast enhancement on CT is homogeneous or it can have a circum enhancement in cystic lesions. ${ }^{6}$

Surgical strategy in TS is generally tailored on the tumor and no definitive recommendations can be made. Because of the difference in the classification systems, lack of volumetric studies and report of trigeminal function, there is an inevitable difficulty in comparing different series, the same as in the case of other complex skull base tumors. Some authors divide the possible approaches into conventional approaches and skull-base approaches. ${ }^{6}$ The conventional approaches include the subtemporal intradural, frontotemporal infratemporal, while the skull base approaches include anterior transpetrosal, zygomatic infratemporal or zygomatic transpetrosal. ${ }^{14}$ Some authors describe the use of adjuvant technical means, e.g. endoscopy, especially in those tumors that extend into multiple cranial compartments. ${ }^{15,16,19}$ As previously mentioned, the goal of surgery should be a complete removal, without sacrifice of neurological function. It must be kept in mind that sometimes, transient neurological deficits can appear after surgery, but these disappear in a few days. ${ }^{20}$ In our experience, the use of a conventional approach is sufficient in most cases, in order to achieve complete removal. Tumors are usually solid and soft and detachment from ICA or nervous structures is performed easily. The preservation of function of the trigeminal nerve is possible in those cases in which the tumor is well delimitated, although this is rarely the case in giant tumors.

We operated this case in two stages. Middle fossa part is extradural subtemporal approach rest part is by retrosigmoid approach.

\section{Conclusion}

In case of giant trigeminal schwannoma stage surgery can safe the patient life and prevent postoperative complication.

\section{References}

1. Russels DS, Rubinstein LJ. Pathology of tumors of the nervous system. 5th ed. London: Edward Arnold 1989.

2. Singh RV, Suys S, Campbell DA, Broome JC: Malignant schwanomma of the cerebellum : case report. Surgical Neurology 1993;39: 128-132.

3. Goel A, Muzumdar D, Raman C. Trigeminal neuroma: analysis of surgical experience with 73 cases. Neurosurgery 2003;52(4):783-90.

4. Coniglio AJ, Miller MC, Walter KA, Crane BT. Trigeminal schwannoma with extracranial extension and brainstem compression. Otol Neurotol 2013; 34(6):e42-4.

5. Fukaya R, Yoshida K, Ohira T, Kawase T. Trigeminal schwannomas: Experience with 57 cases and a review of the literature. Neurosurg Rev 2011;34(2):159-170.

6. Gheorghe Ungureanu, Ioan Stefan Florian. Giant trigeminal schwannomas-case report and a short literature review. Romanian Neurosurgery 2017; XXXI 2:161-164.

7. Ghatak NR, Norwood CW, Davis C: Intacerebral Schwannoma. Surgical Neurology 1975;3: 45-47.

8. Gibson AAM, Hendrick EB, Cohen PE: Intracerebral schwannoma, report of a case. J Neurosurg 1966; 24: 552-557.

9. Feigin I, Ogata J: Schwann cells and peripheral myelin within human central nervous tissues: The mesenchymal character of schwann cells. J Neuropathol Exp Neurol 1971;30: 603-612.

10. Stefanko SZ, Vuzevski VD, Maas Al, van Vroonhoven CC: Intracerebral malignant schwannoma. Acta Neuropathol 1986; 71: 321-325. 
11. Zagardo MT, Castellani RJ, Rees JH, Rothman MI, Zoarski $\mathrm{GH}$ : Radiologic and pathologic findings of intracerebral schwannoma. Am J Neuroradiol 1998;19:1290-1293.

12. Miller RT. Immunohistochemistry in the Differential Diagnosis of Schwannoma and Neurofibroma. The FOCUSImmunohistochemistry, October 2004.

13. Jefferson $\mathrm{G}$. The trigeminal neurinomas with some remarks on malignant invasion of the gasserian ganglion. Clin Neurosurg 1953;1:11-54.

14. Yoshida K, Kawase T. Trigeminal neurinomas extending into multiple fossae: surgical methods and review of the literature. J Neurosurg 1999; 91(2):202-11.

15. Konovalov AN, Kalinin PL, Shimanskii VN, Shapirov OI, Kutin MA, Fomichev D V, Kadasheva BA, Turkin AM, Kurnosov AB. Experience of surgical management of trigeminal schwannomas that simultaneously spread to the middle and posterior cranial fossae. Zhurnal Vopr neirokhirurgii Im N N Burdenko 2014;78(5):23-32.
16. Samii M, Alimohamadi M, Gerganov V. Endoscope-assisted retrosigmoid intradural suprameatal approach for surgical treatment of trigeminal schwannomas. Neurosurgery 2014;10 Suppl 4(4):565-75.

17. Gupta P, Sharma A, Singh J. Solid cystic trigeminal schwannoma with intraorbital extension causing proptosis and vision loss. Asian J Neurosurg 2016;11(4):456.

18. Agarwal A. Intracranial trigeminal schwannoma. Neuroradiol J 2015; 28(1):36-41.

19. Raza SM, Donaldson AM, Mehta A, Tsiouris AJ, Anand VK, Schwartz TH. Surgical management of trigeminal schwannomas: defining the role for endoscopic endonasal approaches. Neurosurg Focus 2014;37(4):E17.

20. Sharma BS, Ahmad FU, Chandra PS, Mahapatra AK. Trigeminal schwannomas: Experience with 68 cases. J Clin Neurosci 2008;15(7):738-743. 